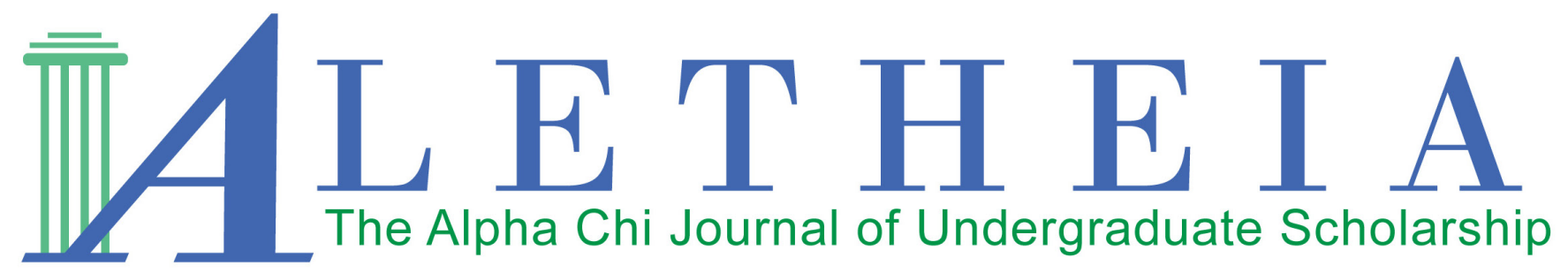

Volume 3 | Issue 2 | 2018

\title{
Euterpe \\ Muse of Lyric Poetry
}

Movement V from Daughters of Olympus for Chamber Nonet

\author{
Aaron Waldrupe \\ Carson-Newman University \\ Tennessee Delta Chapter
}

Vol. 3(2), 2018

Title: Euterpe Muse of Lyric Poetry

DOI:

ISSN: 2381-800X

Keywords: Model, Simulated Demands, Inverse Linear Splines, Monte Carlo Simulation This work is licensed under a Creative Commons Attribution 4.0 International License.

Author contact information is available from tlindblom@alphachihonor.org or kvosevich@alphachihonor.org

\section{Aletheia-The Alpha Chi Journal of Undergraduate Scholarship}

- This publication is an online, peer-reviewed, interdisciplinary undergraduate journal, whose mission is to promote high quality research and scholarship among undergraduates by showcasing exemplary work.

- Submissions can be in any basic or applied field of study, including the physical and life sciences, the social sciences, the humanities, education, engineering, and the arts.

- Publication in Aletheia will recognize students who excel academically and foster mentor/mentee relationships between faculty and students.

- In keeping with the strong tradition of student involvement in all levels of Alpha Chi, the journal will also provide a forum for students to become actively involved in the writing, peer review, and publication process.

- More information can be found at www.alphachihonor.org/aletheia. Questions to the editors may be directed to tlindblom@alphachihonor.org or kvosevich@alphachihonor.org.

Alpha Chi is a national college honor society that admits students from all academic disciplines, with membership limited to the top 10 percent of an institution's juniors, seniors, and graduate students. Invitation to membership comes only through an institutional chapter. A college seeking a chapter must grant baccalaureate degrees and be regionally accredited. Some 300 chapters, located in almost every state, induct approximately 11,000 members annually. Alpha Chi members have been "making scholarship effective for good" since 1922. 


\title{
Euterpe Muse of Lyric Poetry
}

\author{
Movement V \\ From \\ Daughters of Olympus \\ for Chamber Nonet
}

\author{
Aaron Waldrupe \\ Carson-Newman University \\ Tennessee Delta Chapter
}

Program Notes

The Daughters of Olympus suite for chamber nonet was inspired by the mythological nine muses. The nine movements semi-programmatically evoke qualities of the muse for which each one is named. Additionally, each movement possesses at least one theme or motif that is echoed in the other movements. For example, Polyhymnia's Divine Theme is quoted partially or wholly in each movement.

In Euterpe, muse of lyric poetry, the ensemble simulates a choral ensemble. Beginning with an introspective horn call, quietly growing into a chorale, the mood shifts from peaceful solemnity into an agitated state. Led by the upper voices, an almost primal-but structured-chant arrives: a modal adaptation of Erato's Love Theme in the horns while a quote of a Delphic Hymn is subtly interwoven contrapuntally on a pizzicato cello. With a swell, the horns and strings smooth the chant's motion, allowing an introspective attitude to appear again, now more mysteriously. The ecclesiastical song of the woodwinds is grounded by the pizzicato strings, which soon transition into a drone-like passage inspired by Ars Subtilior with the winds introducing a new chant to float upon the drone, reminiscent of the hymn "Tell Me the Story of Jesus." The emotions build up gradually, sometimes longingly, sometimes contentedly, until Polyhymnia's Divine Theme is stated as a chorale with the opening horn call used as a compliment to the hymn. The ecclesiastic song and drone chant are used as a descant. Finally, the full choir finds resolution in a firm major tonic chord. 


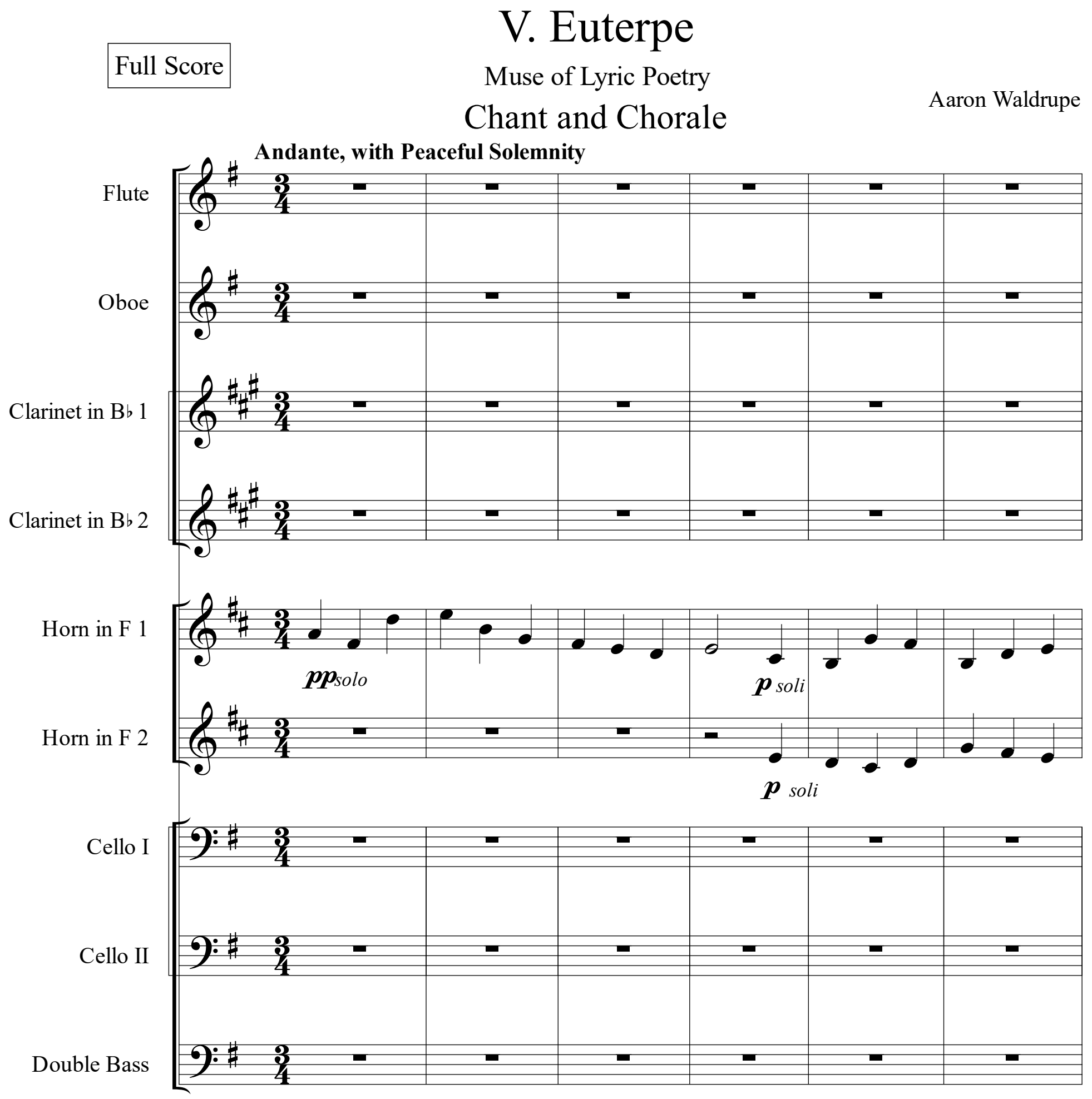


V. Euterpe

9
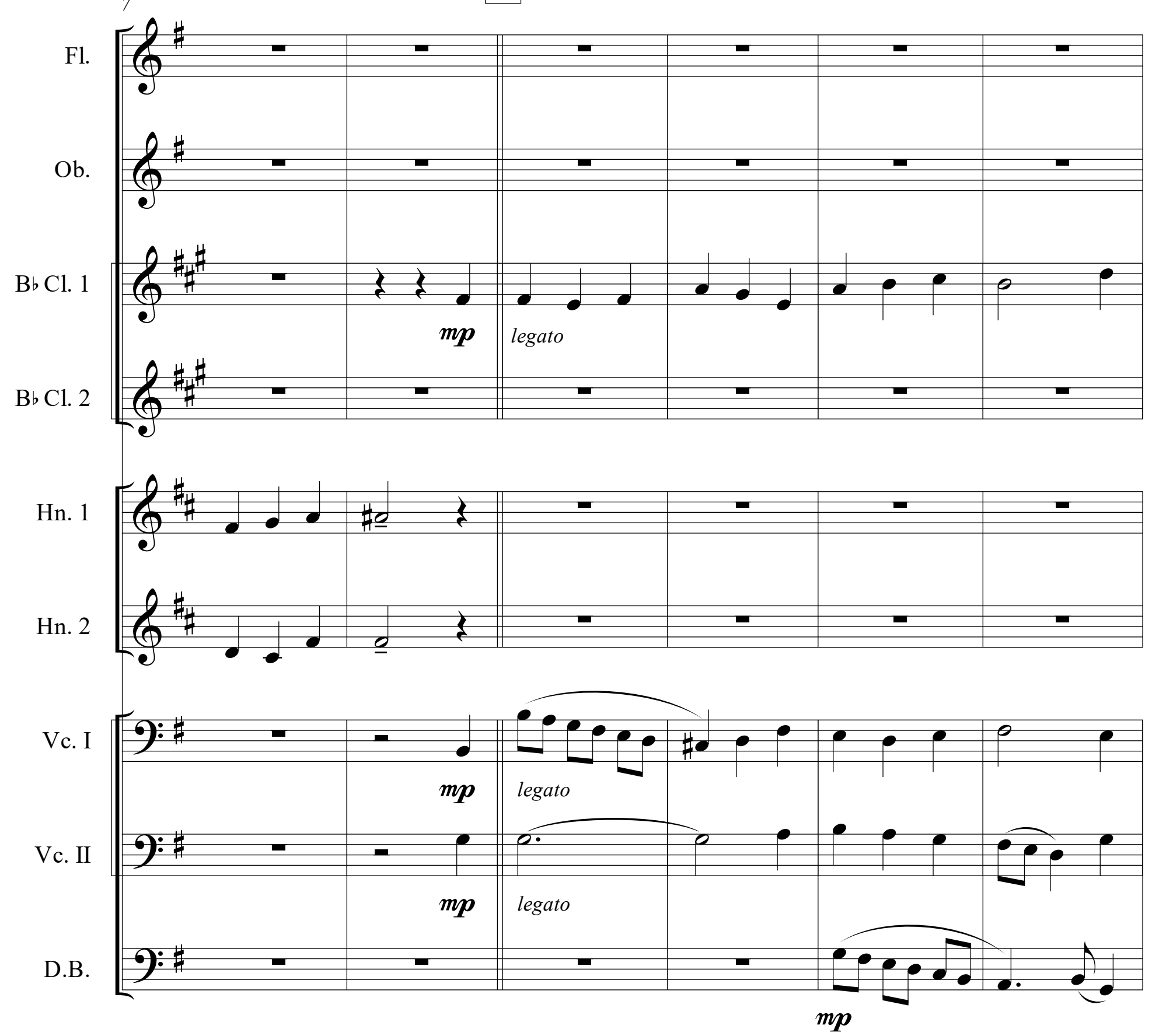
V. Euterpe

5

Fl.

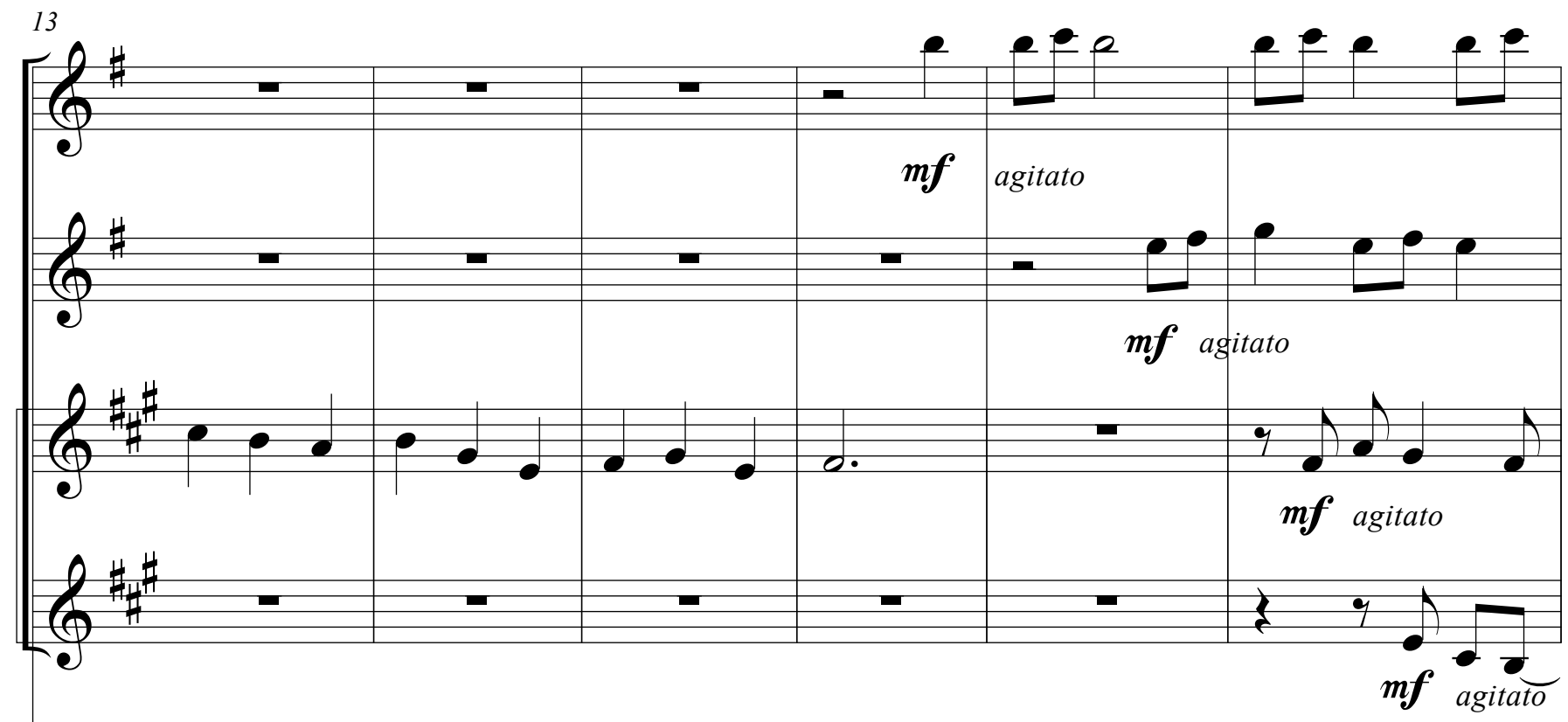

Bb Cl. 1

Bb Cl. 2

Hon. 1

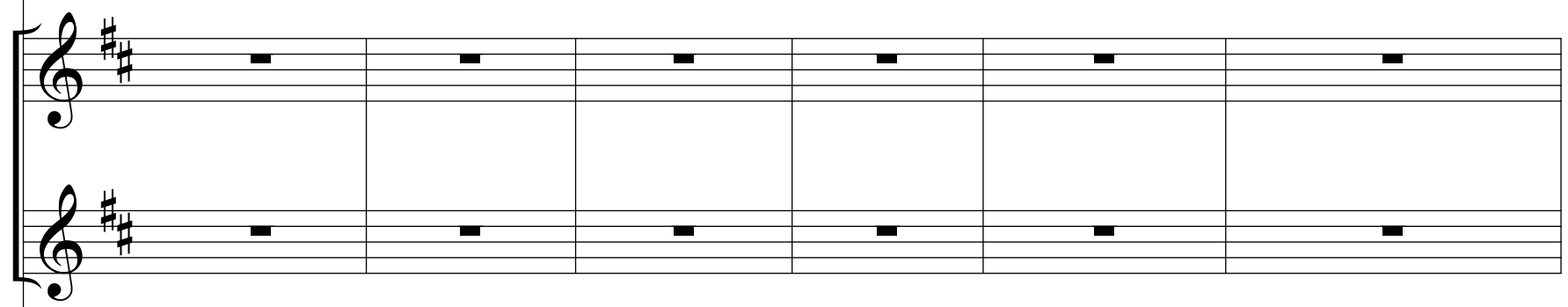

Hn. 2

pizz.

Vc. I

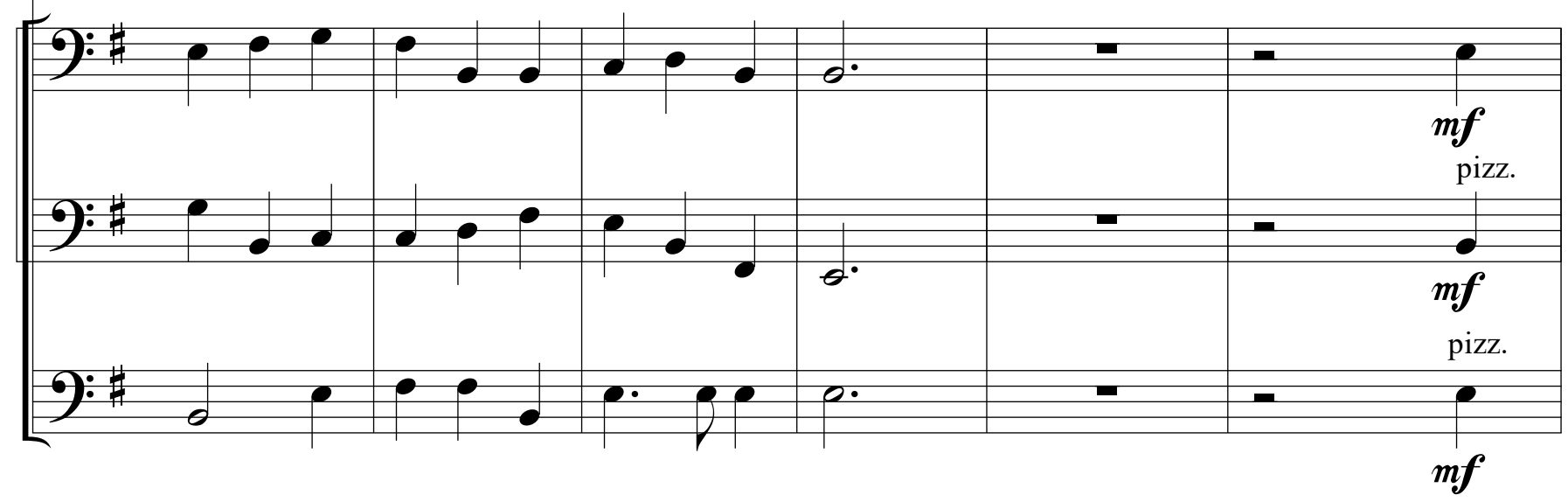




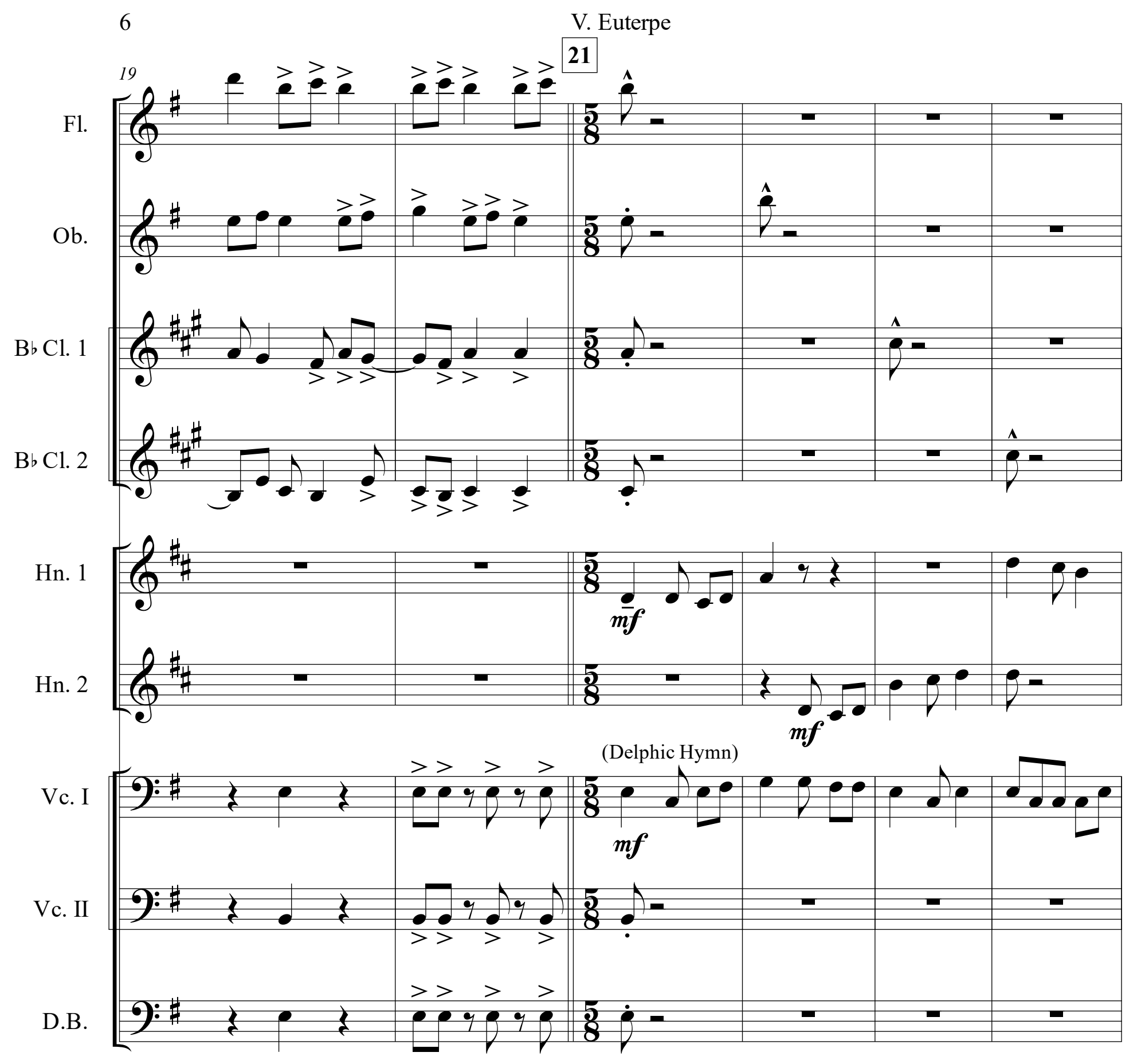



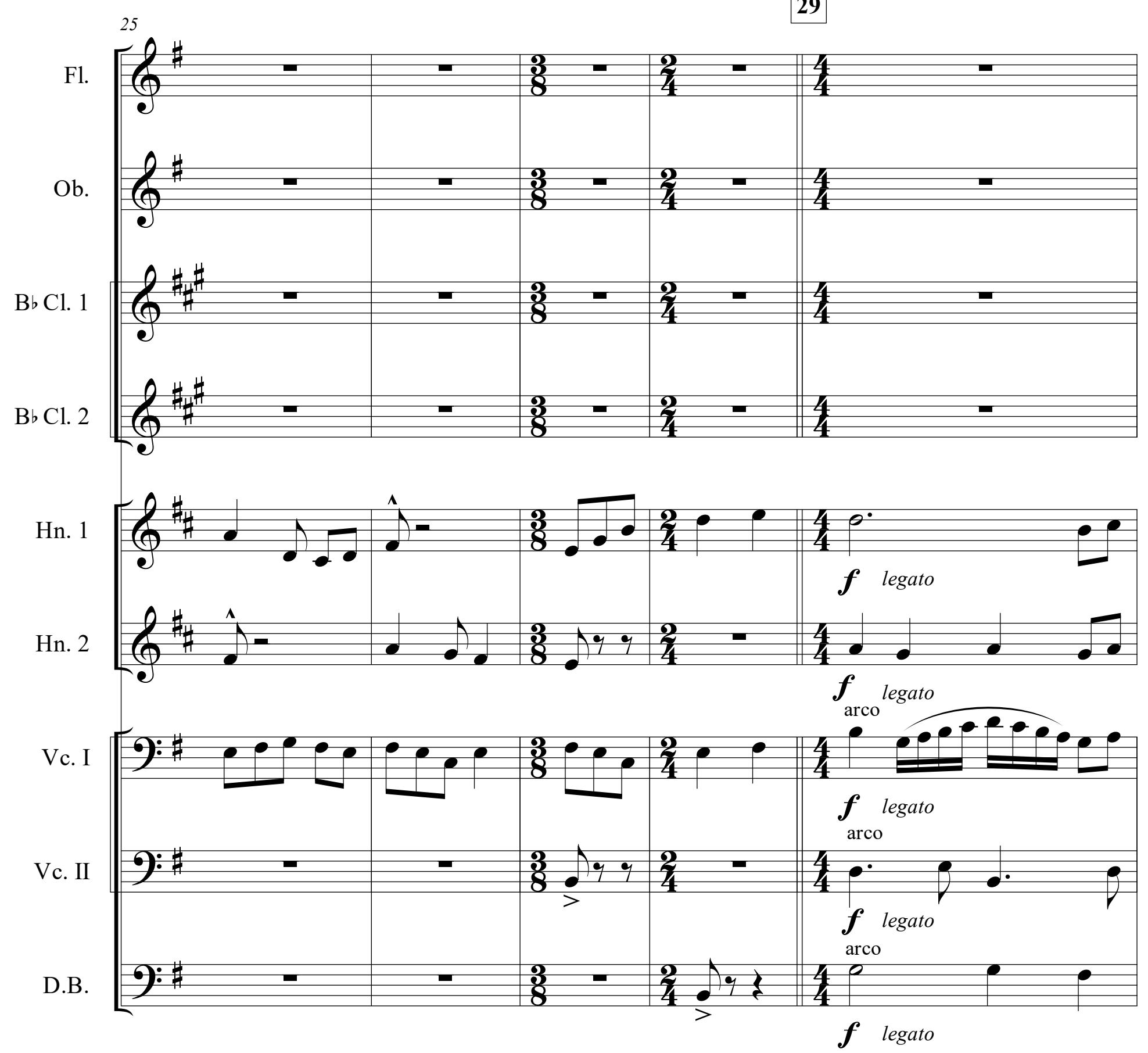

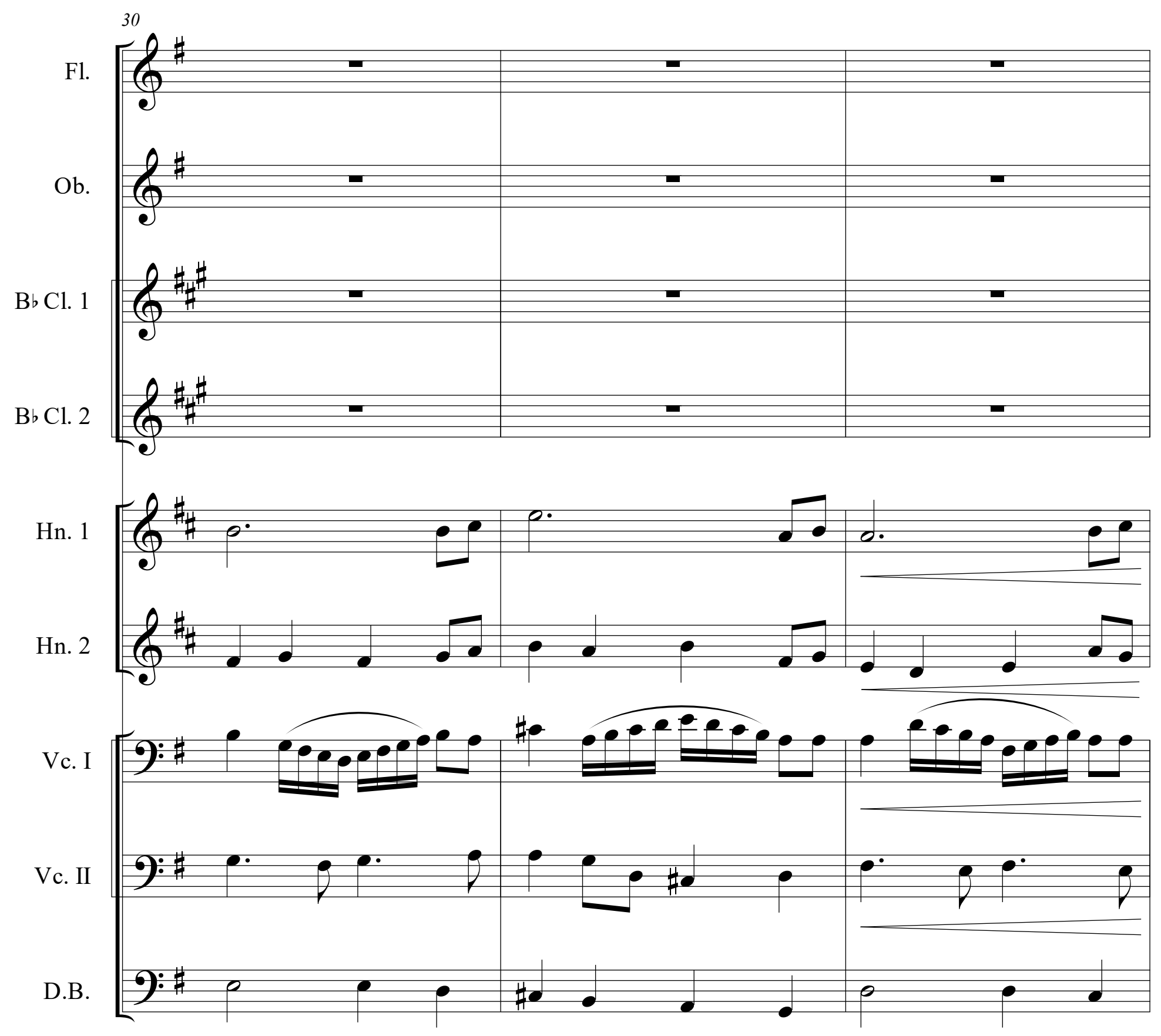


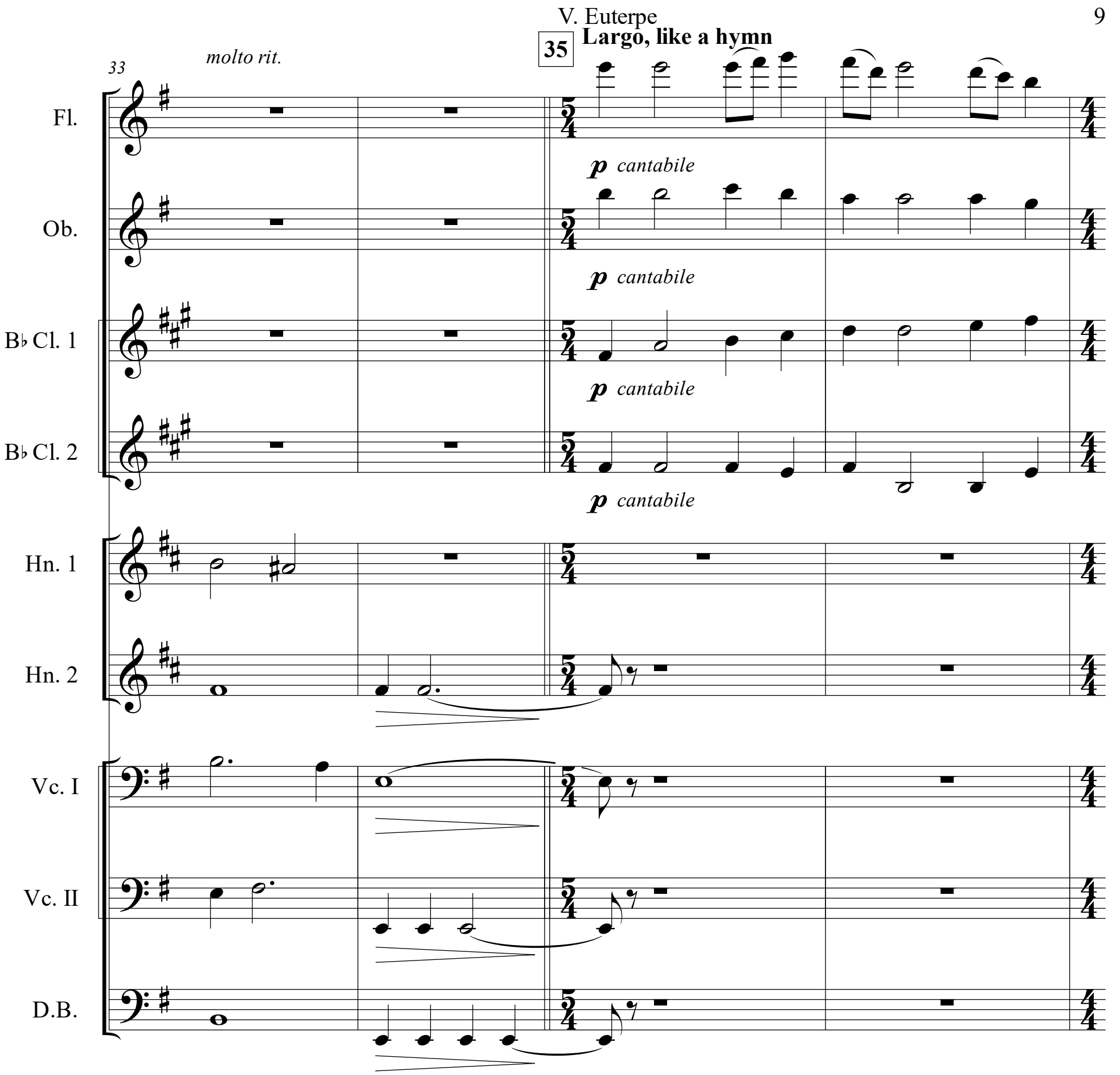




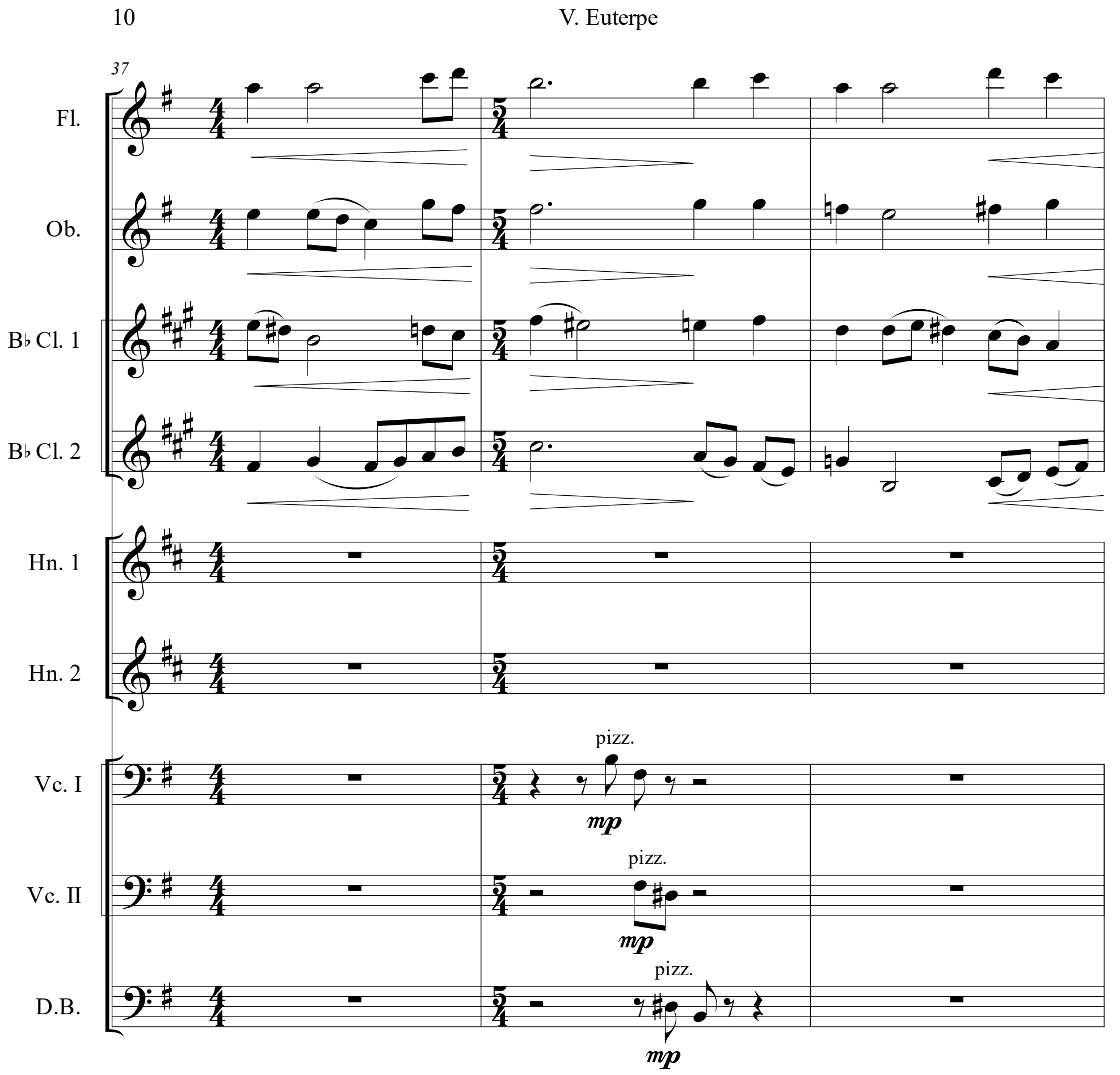




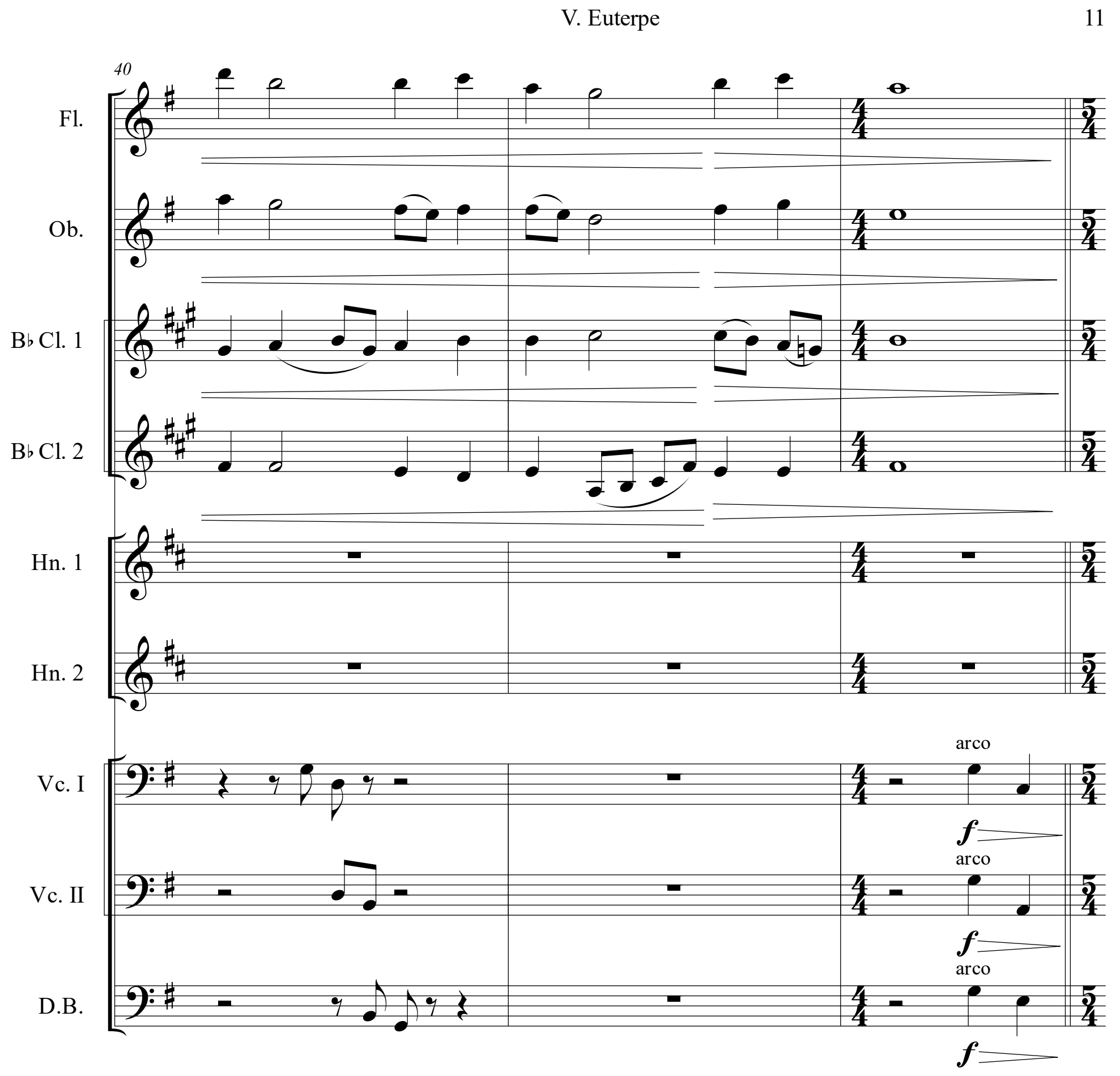


12

V. Euterpe

43

Fl.

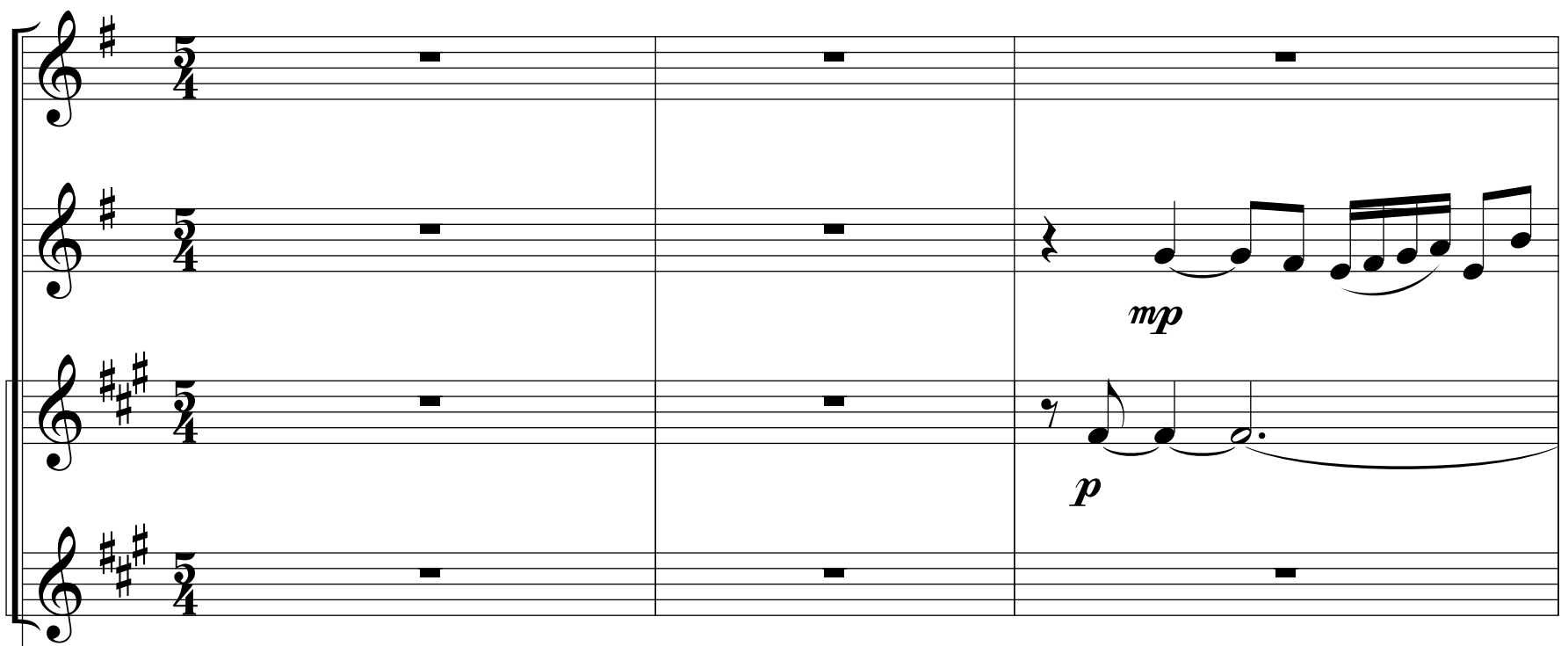

Hr. 1

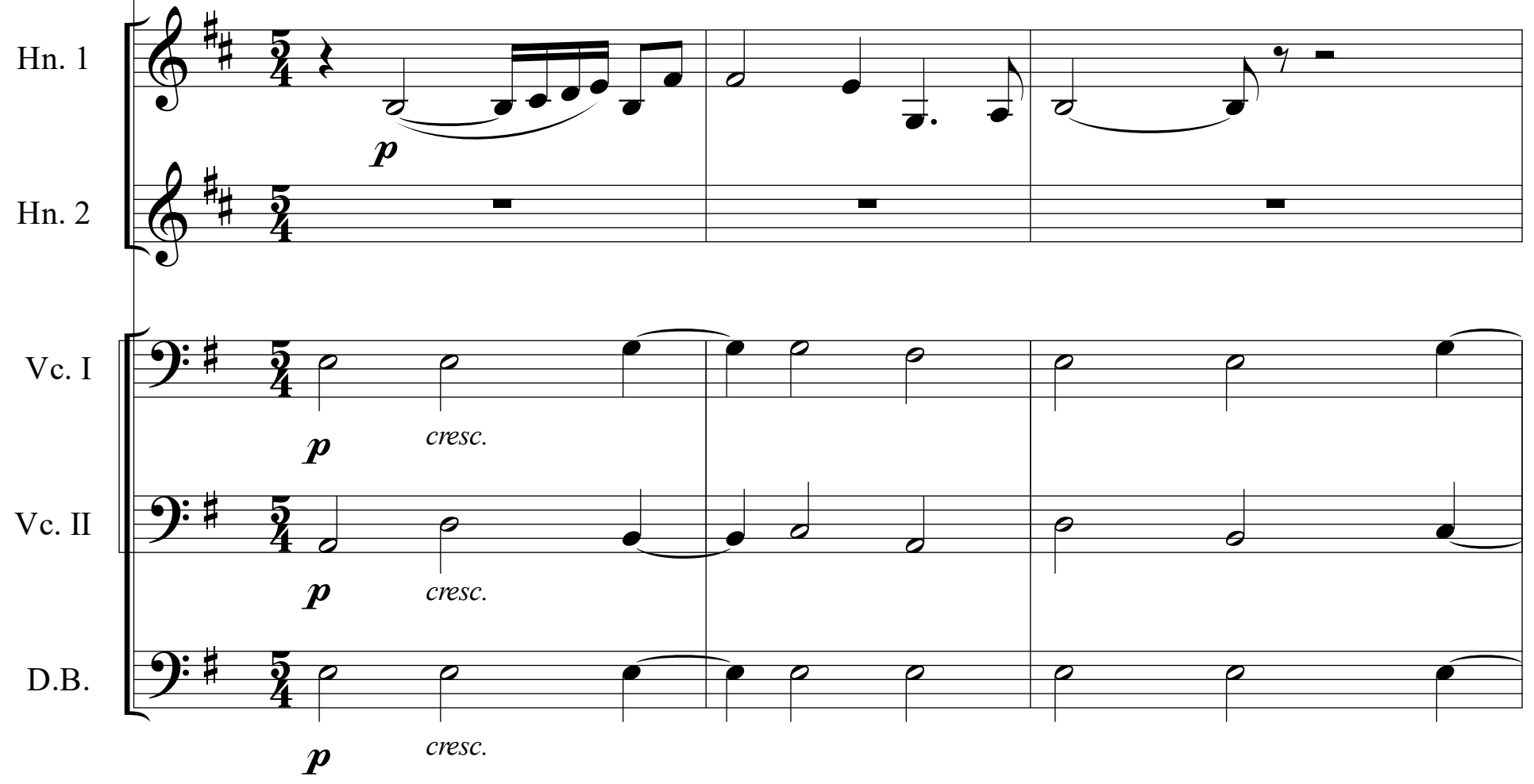

Hr. 2

Bb Cl. 1

Bb Cl. 2 
V. Euterpe

13

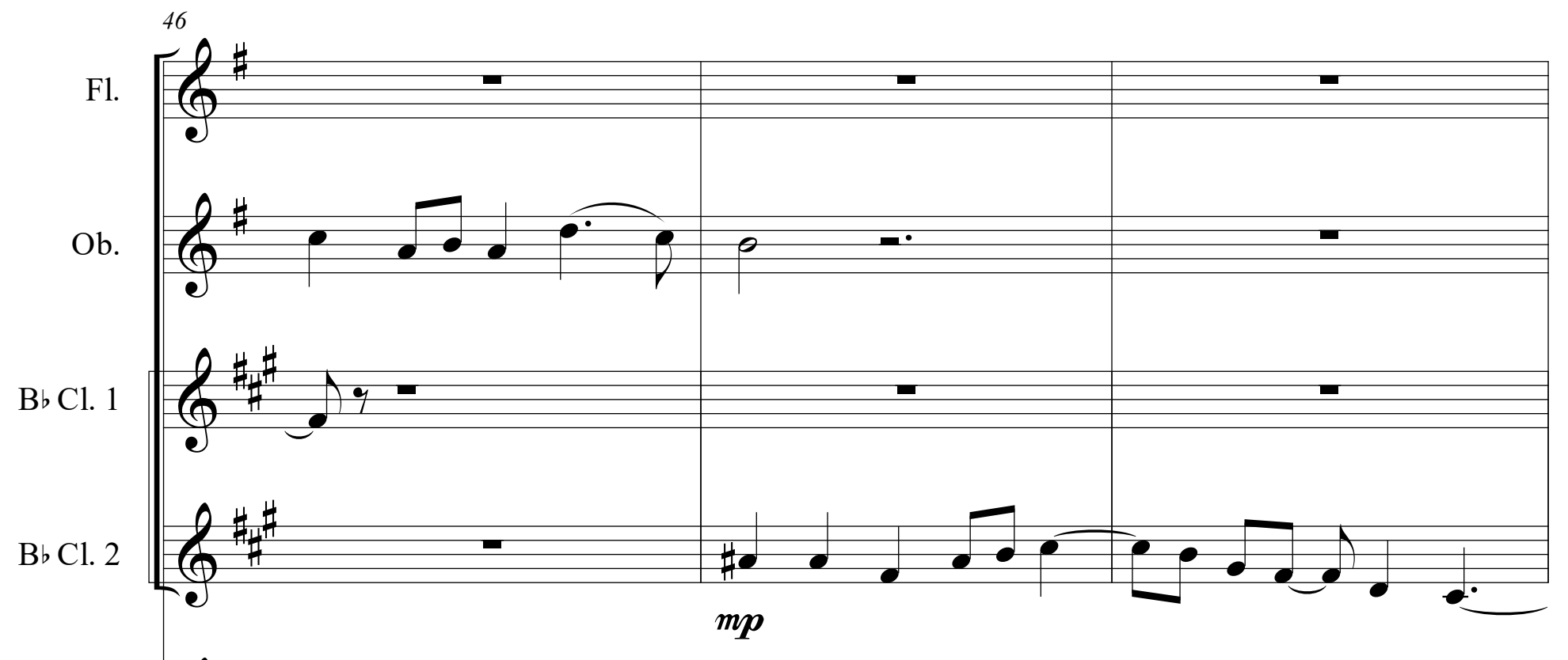

Hon. 1

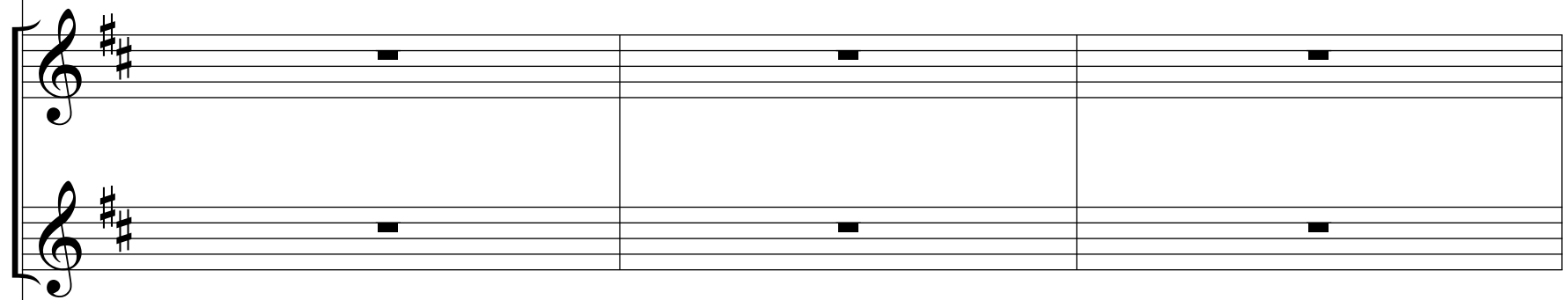

Vc. I

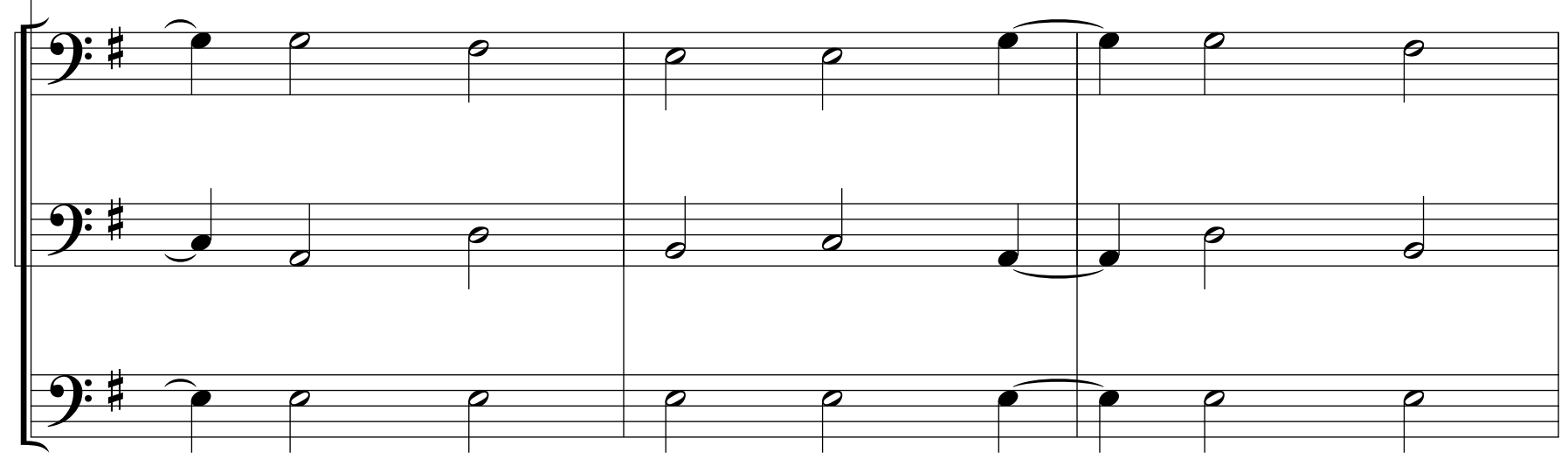



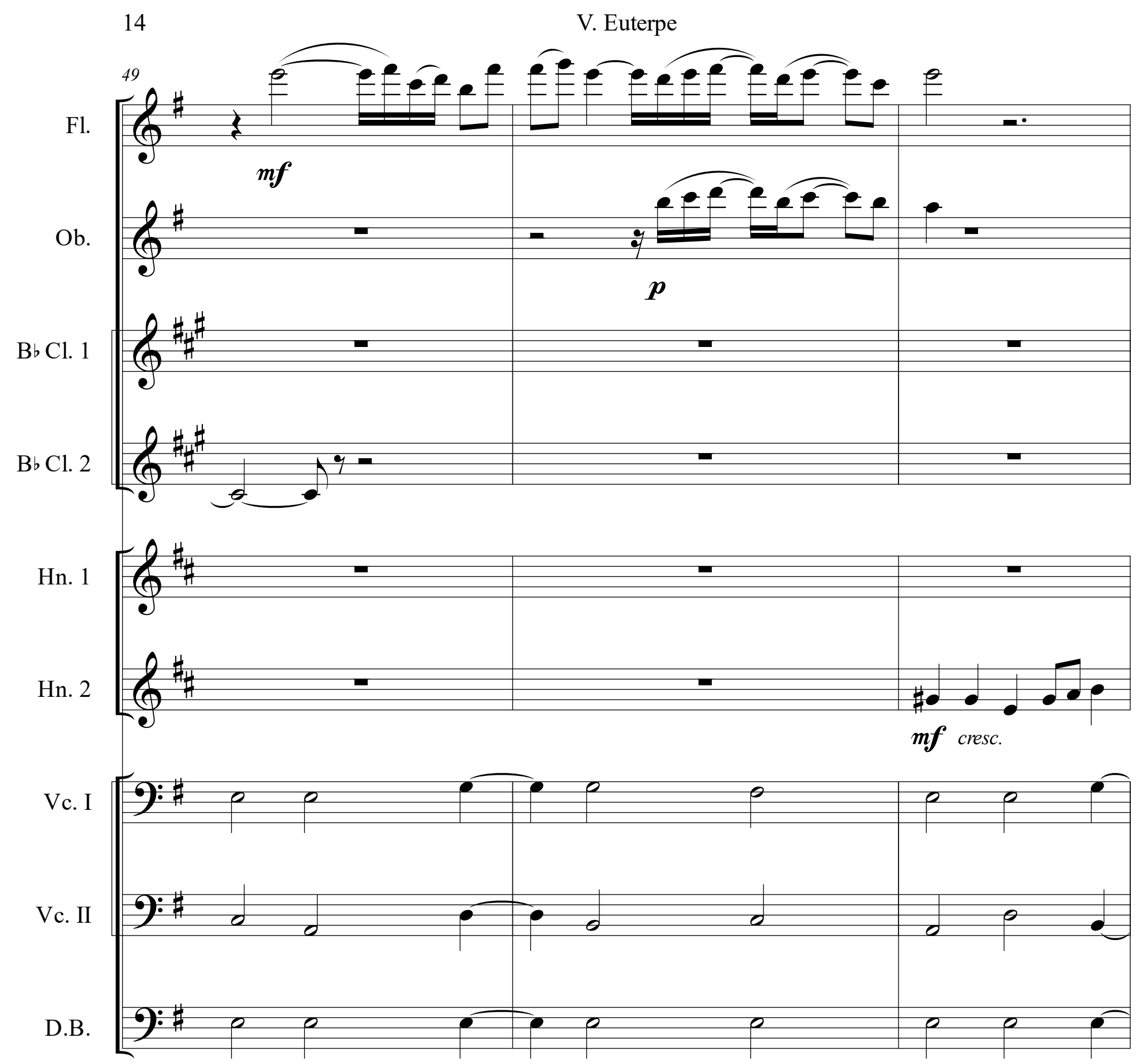


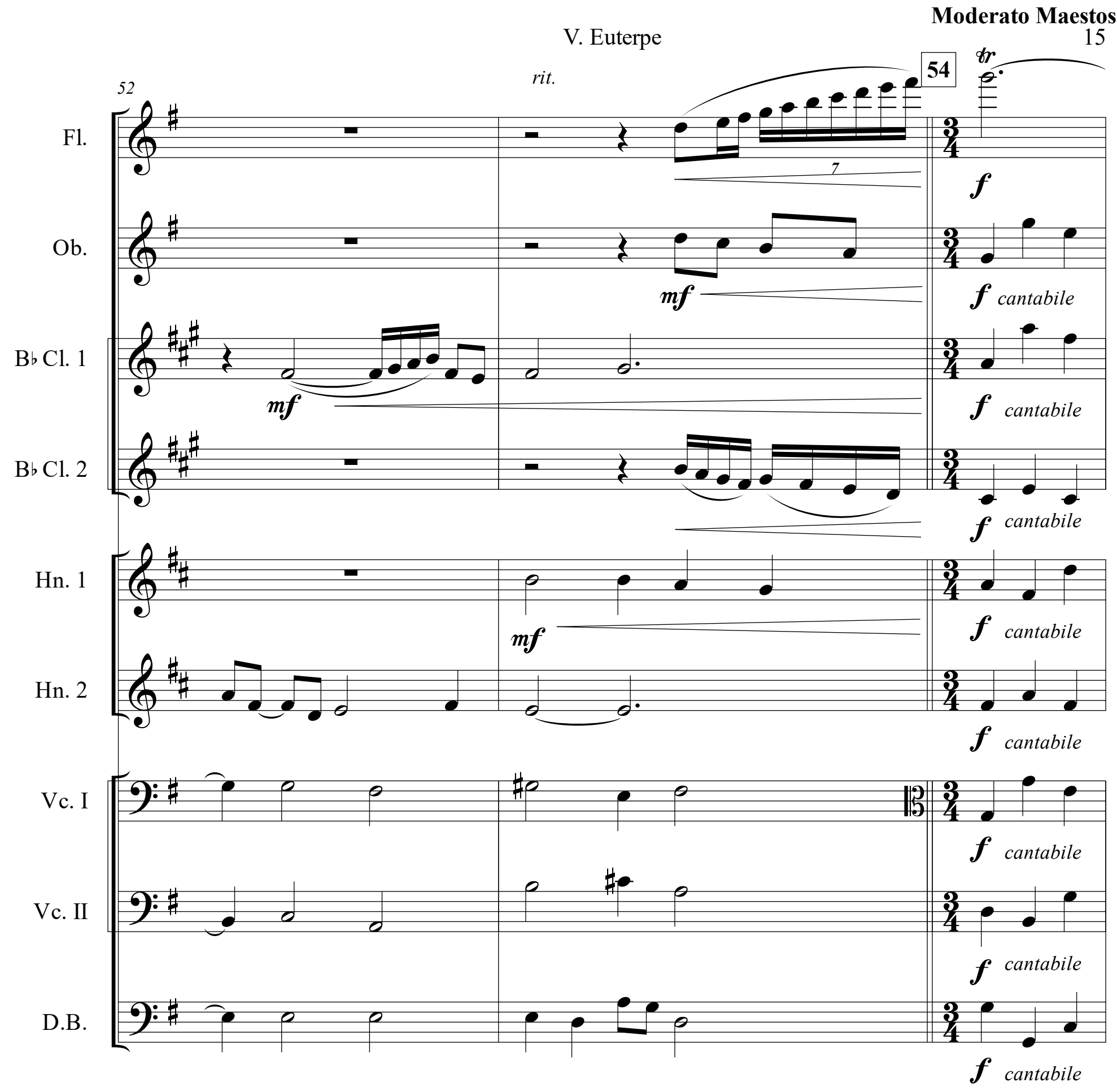




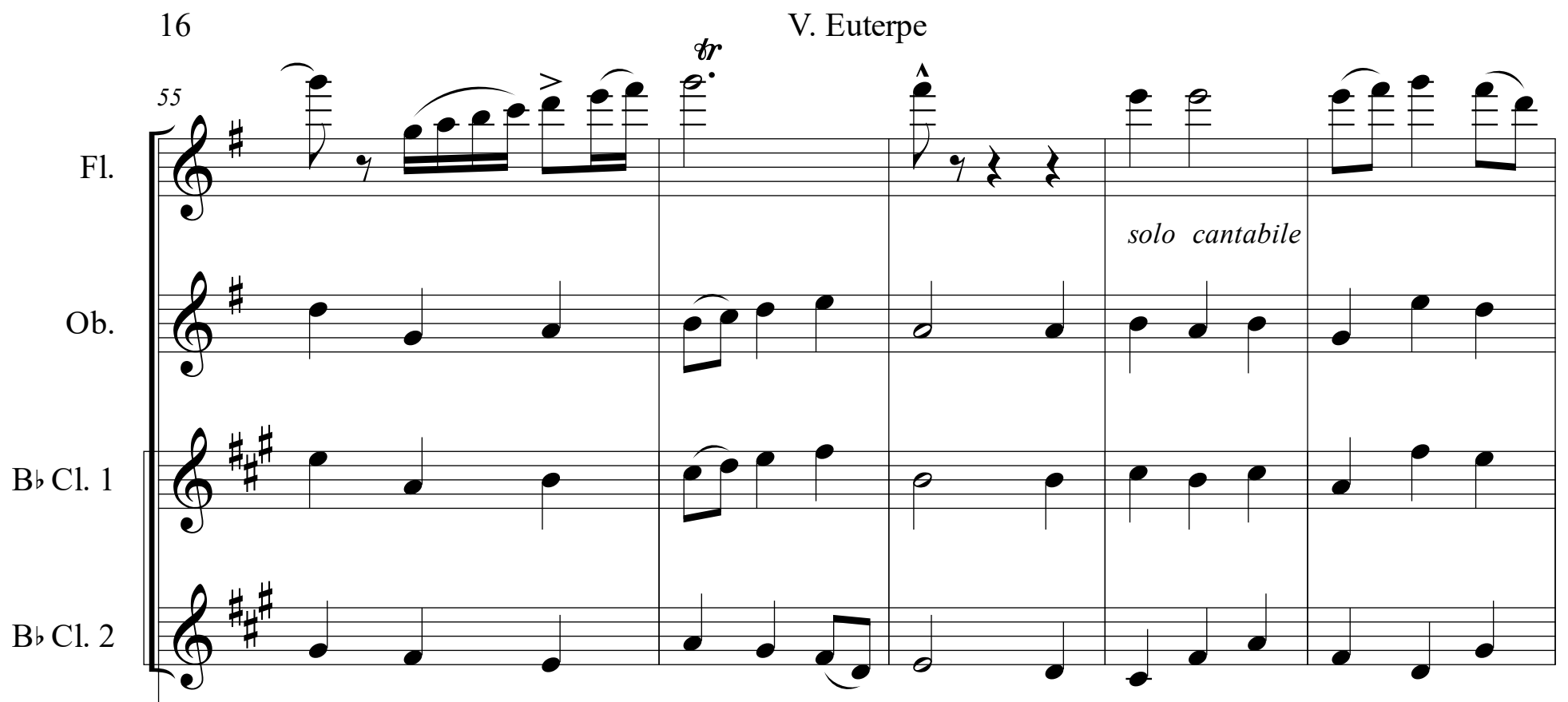

Hn. 1

Hn. 2

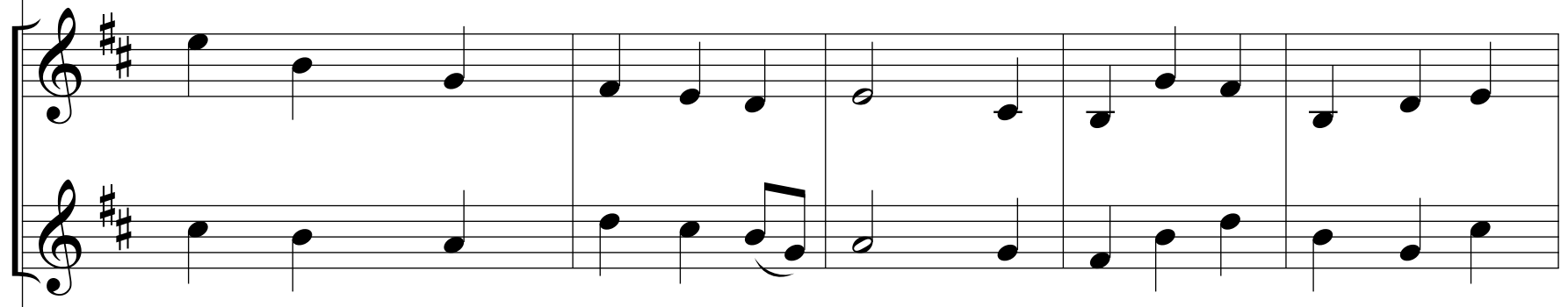

Vc. II

D.B.

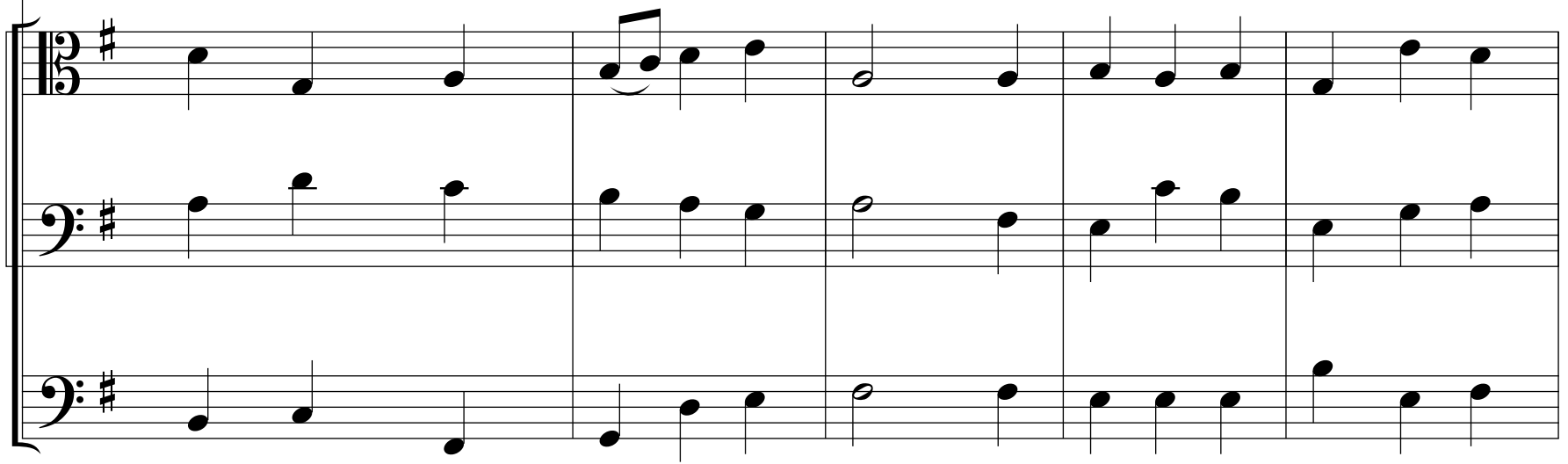




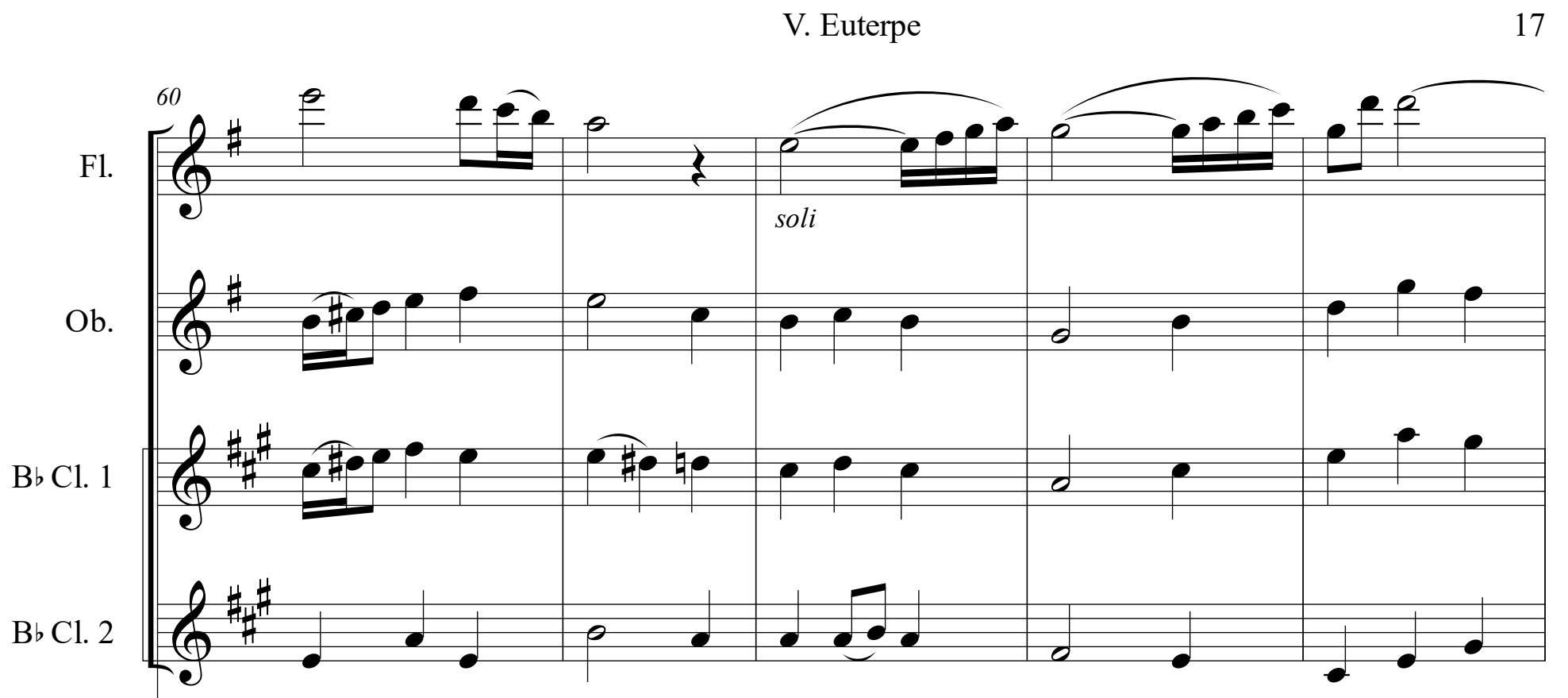

Hn. 1

Hn. 2

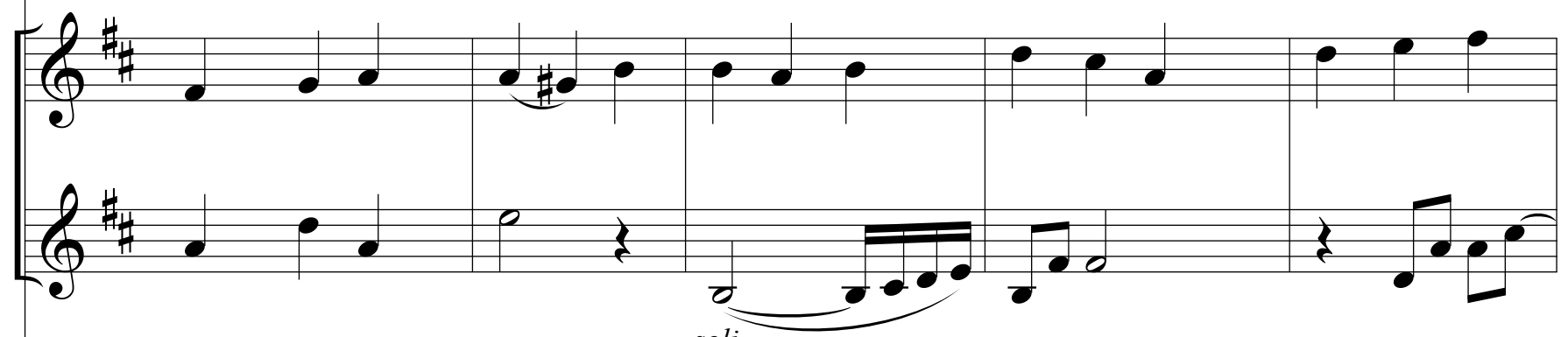

Vc. I

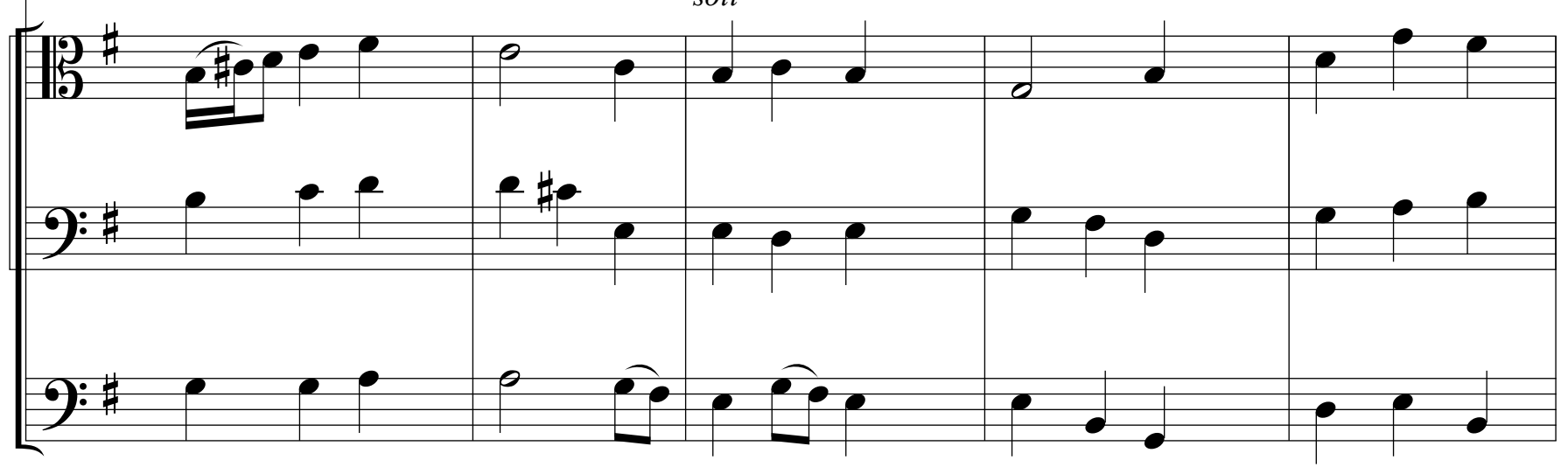




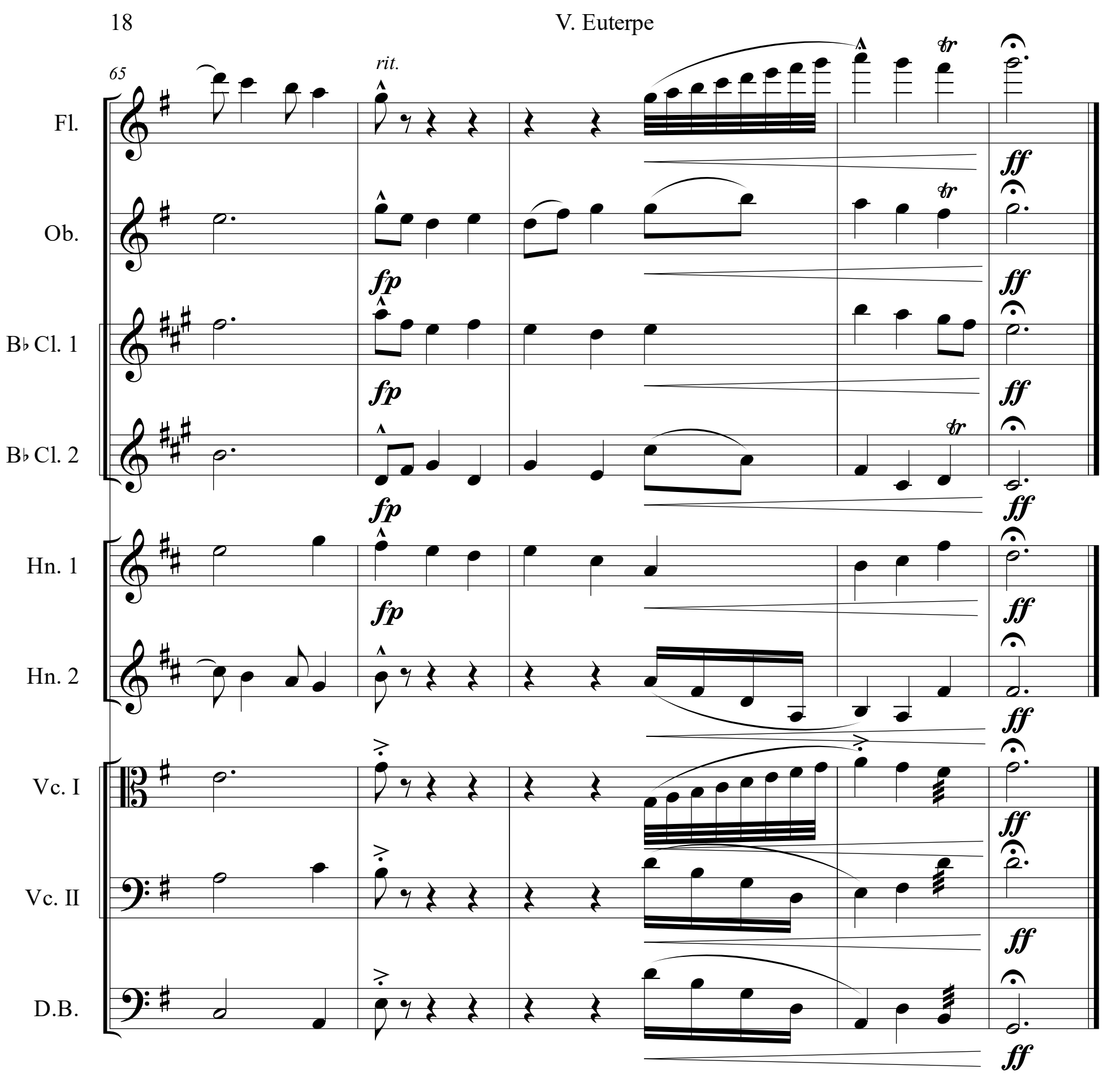

